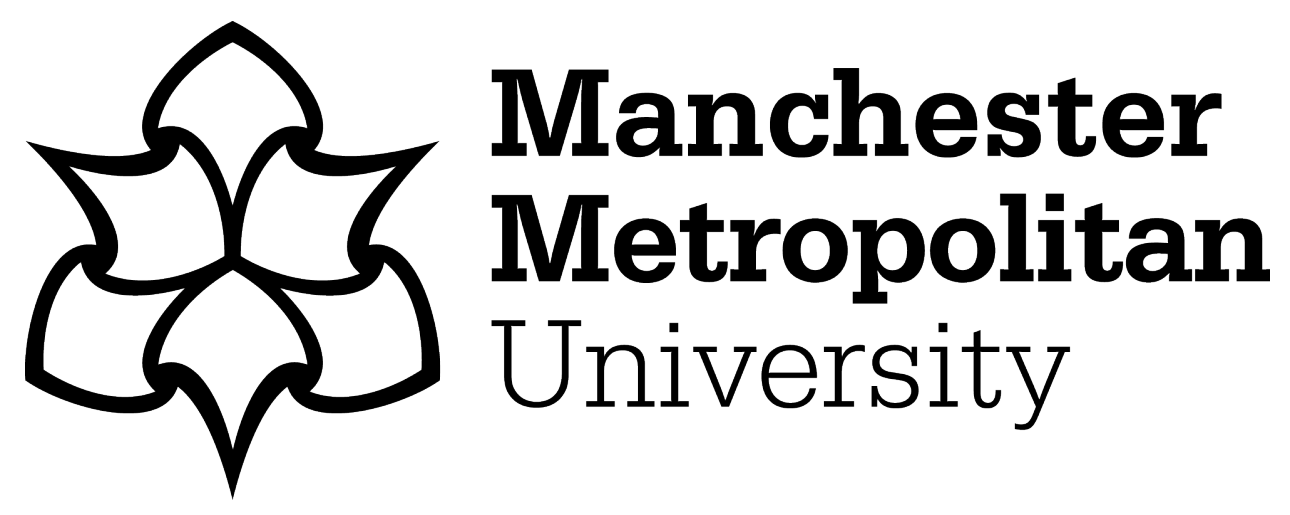

Edwards, P ORCID logoORCID: https://orcid.org/0000-0002-5814-4184 (2016) Closure through resilience: The case of prevent. Studies in Conflict and Terrorism, 39 (4). pp. 292-307. ISSN 1057-610X

Downloaded from: https://e-space.mmu.ac.uk/312/

Version: Accepted Version

Publisher: Taylor \& Francis

DOI: https://doi.org/10.1080/1057610X.2016.1117326

Please cite the published version 


\title{
Closure through resilience: the case of Prevent
}

Phil Edwards

Mancester Metropolitan University

\begin{abstract}
This paper argues that resilience in the face of terrorism, at the level of a political system, is best conceptualised as a response to disruption of the political sphere leading to the destabilisation of political relationships; this disruption is triggered not by violence as such, but by the forceful incursion of a would-be political actor denied representation and legitimacy. The challenge posed by political disruption and destabilisation is related to a typology of political systems, suggesting that the most resilient political systems are also those exhibiting executive unity together with a high degree of democratic openness. The ideological negotiation required to deal with political disruption is related to the model of the social movement "cycle of contention"; it is argued that engagement with terrorist disruption may similarly take both inclusive and exclusive forms, with consequences for the openness and hence the future resilience of the system. The arguments and appeals used to support the British government's "Prevent" counter-radicalisation initiative, launched in 2003 and reworked in 2009 and 2011, are analysed as a source of data on a process of engagement with a disruptive political incomer; the engagement is shown to be emphatically exclusive.
\end{abstract}




\section{Introduction}

The British government's ideological counter-terrorist programme Prevent can be understood as a developing set of resilience strategies, responding both to the disruption threatened by terrorist acts and the political destabilisation which follows disruption. This article argues that societies vary in their vulnerability to both disruption and destabilisation. The labelling of unacceptable forms of political self-assertion as terrorism is characteristic of a society with a high level of vulnerability to disruption. Responses to disruption may be more or less destabilising: the path taken depends partly on the underlying characteristics of the polity and partly on political choices, determined by patterns of politicization and episodes of politicking.

The vulnerability of contemporary British society to disruption is exemplified by the ways in which Prevent, and twenty-first-century British counter-terrorist policy more broadly, frame terrorism in fundamentally ideological terms. Strategies of resilience implemented in response to this ideological threat have focused on the risk of destabilisation: political closure has been imposed, redrawing the ideological boundaries of the polity. The result, ironically, has been to make the polity more, rather than less, vulnerable to disruption.

\section{Resilience, openness and unity: a typology of states}

Malkki and Sinkkonen define political resilience as "the way that continuity and transformation take place in the face of specific endogenous or exogenous shocks in all aspects of political life" 1 . This paper views resilience more narrowly, as a class of responses to the disruption and destabilisation caused by exogenous shocks - or shocks which are framed as exogenous. ${ }^{2}$ 
Exogenous shocks are events originating outside the political system - initiated by forces not already recognised and legitimated as political actors - which disrupt the polity by threatening to impose unpredictable costs on its continuing operation. Although they are often analogised to acts of war or natural disasters, exogenous shock events do not have to be non-local in origin or non-political in nature. While terrorist attacks are a key example of disruptive shock, disruption may take many forms.

What events are experienced as disruptive shocks will vary according to the properties of the political system affected: specifically, the openness or closure of the polity's political boundaries. An autocracy in which all decisions were made at the whim of the autocrat, with no public discussion allowed, would effectively define all political action (whether policy, politicization or politicking) as exogenous, i.e. as taking place outside the limits of the permissible. In such a setting, the self-assertion of any political actor would be highly disruptive to the continuing functioning of the autocracy. At the other extreme, we can imagine a system in which continual public consultation and benign surveillance made it possible to grant effective political representation immediately to every interest group that formed - non-working mothers, white racists, nonunionised call centre workers, etc. Such a polity would have no "outside" and would experience no exogenous shocks, other than genuinely non-local or extra-political events (acts of war and God).

State openness and closure in this sense - the degree to which a polity is able and willing to accommodate new entrants - are related but not identical to the older ideas of state strength and weakness. Kriesi suggested an inverse relationship between the "output" capacity of a state and the opportunities it offers for "input"; a "strong" state can both impose its will and resist pressure from below, whereas in a weak and ineffectual state, "[f]ragmentation, lack of internal coordination, and 
lack of professionalisation multiply the points of access". ${ }^{3}$ However, in practice fragmentation and lack of professionalism in government does not necessarily create numerous openings for influence from below. The history of the governments of post-war Italy, to name one example, suggests that these conditions are equally compatible with very low levels of accountability, enabling elite power to be captured by a loose and partially competitive association of cliques; thus Ginsborg noted "the archipelago nature of the [Christian Democrat] state". ${ }^{4}$

It may be more informative to think in terms of a four-way typology of state openness and strength. Combining two variables - the multiplicity or not of centres of power, and of points of access to the political system - suggest four ideal-typical possibilities (see Table 1). The ideal "autocracy" (corresponding to Kriesi's "strong state") is characterised by a high concentration of power and few points of influence; the "anarchy" (Kriesi's "weak state") has multiple points of influence over multiple distinct power centres. The ideal "direct democracy" combines a plurality of points of influence from below with the "output" strength of an unchallenged executive. Lastly, the ideal "oligopoly" combines an autocracy's closure to outside influence with the executive weakness of a polycentric system.

\section{Table 1: Types of state defined by concentration of power and points of access ABOUT HERE}

The monolithic autocracy needs no explanation; most capitalist democracies approximate more or less closely to the oligopoly, combining a limited range of formal mechanisms of accountability with the effective dominance of multiple distinct power structures (e.g. finance capital, the media industry, the police and intelligence agencies, etc). By contrast, real-world examples of the state types in the left-hand column are rare; the "anarchy" type is prone to collapse (or capture by aspiring oligopolists), while the "direct democracy" figures mainly as an ideal (this model has been 
said to characterise the 'democratic centralist' structures adopted by Leninist parties and Communist states). Democratic states can be considered as lying on a continuum of greater or less effectiveness and accountability, between the ideal of the "direct democracy" (highly effective centralised power, high accountability through multiple points of influence) and the more dystopian extreme of the pure "oligopoly" (ineffectually dispersed elite power, accountability limited through lack of points of influence).

The horizontal dimension - "openness" - corresponds to the degree to which external influences are likely to be interpreted as a disruptive exogenous shock. Both the "anarchy" and the "direct democracy" state can in principle accommodate new political entrants without disruption. Both "oligopoly" and "autocracy", by contrast, have a definite boundary between legitimate political actors within the polity and disruptive forces outside it.

This four-way typology also allows us to differentiate between disruption and destabilisation. Destabilisation refers here to the forced (or accelerated) re-negotiation of relationships within a polity; it is not caused by disruption but by the system's response to it. In Innes's formulation, "[t]errorism seeks to manufacture uncertainty to induce a reaction that destabilizes a social order" the disruptive event creates uncertainty, the reaction destabilises. Disruption does not inevitably lead to destabilisation; disruptive events may lead to an adjustment of the balance of forces when normality returns (as in the aftermath of the Madrid train bombing), but they may also have the effect of reinforcing a political status quo. Repertoires of resilience include both responses to disruption and ways to manage the consequent destabilisation. Bourbeau's three-way typology of forms of resilience, which is also discussed in the introduction of this special issue "resistance and maintenance", "change at the margins" and "openness and renewal" 6 - distinguishes between forms of resilience involving lower and higher levels of destabilisation. 
Both the "anarchy" and - more significantly - the "oligopoly" state types are vulnerable to destabilisation; the "autocracy" and "direct democracy" are not. These alternatives follow from the relative plurality of the system's centres of power; they are thus independent of the property of vulnerability to disruption, which follows from the existence of points of access to the system. "Direct democracy" and "autocracy" state types are less vulnerable to destabilisation, as they are based on a single force's monopoly of power; any new contender will tend to be either absorbed or repressed. (One sign of the degeneration of a purported "direct democracy" into an "autocracy" is precisely the relabelling of previously legitimate political expression as crime, as in the case of the post-war development of the Soviet-allied states of Eastern Europe.) By contrast, polities with multiple power centres are based on relationships among key (recognised) political forces, whether these be competing political blocs or non-party-political institutions (the Church, the banking industry, the corporate media etc). The self-assertion of a new contender will tend to destabilise these relationships; this will lead to a period of more or less contentious adjustment, ending with the acceptance or exclusion of the newcomer. For an "anarchic" polity, existing in a state of instability, a new political entrant would bring further instability but not disruption. In an "oligopoly", however, the self-assertion of a new political actor will cause disruption, after which existing actors' reactions will cause destabilisation; equilibrium will be restored through a period of contentious negotiation resulting in the inclusion or exclusion of the newcomer.

\section{Terrorism as communication, terrorism as ideology}

Despite the prominence in collective memory of the catastrophic events of 11 September 2001, it has never been the norm for attacks denounced as terrorist to have high death tolls. It is worth comparing the 31 deaths on British soil from terrorist attacks in the fifteen years from 1990 to 2004 
inclusive $^{7}$ with the 755 deaths in police custody in England and Wales in the same period ${ }^{8}$, or the 3221 road traffic deaths reported in Britain in 2004 alone. $^{9}$

The key disruptive quality of terrorism, as a form of exogenous shock, is communicative. As Waldron suggests, terrorism "looks to the possibility of creating a certain psycho-social condition, $\mathrm{R}$, in a population that is radically at odds with the range of psycho-social states $\left\{\mathrm{N}_{1}, \mathrm{~N}_{2}, \ldots \mathrm{N}_{\mathrm{n}}\right\}$ that the government wants or needs or can tolerate in its subject population." ${ }^{10}$ While Waldron assumes that this disruptive effect is a means to an end - extortion of concessions from the government - this secondary assumption is not required; rather, we can surely argue that adoption of the belief that Britain should withdraw immediately from Afghanistan or from Northern Ireland, or that Western society should be organised along Islamist lines, is itself an example of the unwanted condition R. The crucially disruptive property of a terrorist attack - differentiating it from any other incident of homicide or criminal damage - thus lies in its expression of inadmissible political agency, in a form which cannot be repressed and hence cannot be ignored.

It follows, crucially, that the denial of any avenue of representation to a potential political actor will itself make that actor's self-assertion disruptive, when it is carried out forcefully enough not to be overlooked. In the British context, this association between ideological exclusion and concepts of terrorism has been particularly evident since counter-terrorist policy began to focus on the threat of Islamist terrorism. This shift which can be dated most conveniently to the Terrorism Act 2000, formulated after the Provisional IRA's permanent ceasefire of 1997 and Al-Qaida's first attack on US targets in 1998.

The Terrorism Act's definition of "terrorism" sets the scene. The Act's predecessor, the Prevention of Terrorism (Temporary Provisions) Act 1974, had defined terrorism as follows: 
'terrorism' means the use of violence for political ends, and includes any use of violence for the purpose of putting the public or any section of the public in fear. ${ }^{11}$

This brief definition is buried in section 9 of the Act, among definitions of terms such as "port" and "ship".

By contrast, the Terrorism Act opens as follows:

(1) In this Act "terrorism" means the use or threat of action where

(a) the action falls within subsection (2),

(b) the use or threat is designed to influence the government or to intimidate the public or a section of the public, and

(c) the use or threat is made for the purpose of advancing a political, religious or ideological cause.

(2) Action falls within this subsection if it

(a) involves serious violence against a person,

(b) involves serious damage to property,

(c) endangers a person's life, other than that of the person committing the action,

(d) creates a serious risk to the health or safety of the public or a section of the public, or

(e) is designed seriously to interfere with or seriously to disrupt an electronic system.

(3) The use or threat of action falling within subsection (2) which involves the use of firearms or explosives is terrorism whether or not subsection (1)(b) is satisfied. ${ }^{12}$ 
Terrorist acts are now defined as violent acts (defined and specified in some detail), carried out with political ends and with the purpose of creating an effect on third parties - which may be either influence over the government or intimidation of the public.

The 2000 definition is thus considerably more flexible and precise than the 1974 definition in terms of the purposes and goals of "terrorist" action. With regard to the actions themselves, the 2000 definition is also much more capacious. Clauses 2(c) and 2(d) put different forms of endangerment on a par with actual violence against persons and property; to create a risk to an individual or a group may be as much a terrorist act as attacking them directly. Clause 2(e) introduces intention, in the specific case of attacks on electronic systems: an action qualifying under this clause may not have caused any damage or risk, but merely have been intended to do so. The opening words of clause 1, finally, expand the whole definition further still, by including the threat of any of these types of action: given the appropriate aims and purposes, a terrorist act may be committed by threatening to bring about physical injury, property damage, endangerment of life, the creation of a risk to public health and safety or an intervention designed to disrupt an electronic system.

Terrorism - the core concept of the Act - is thus defined in terms of ideology and intention rather than purposeful action. Taken literally, the 2000 definition would imply that a vast range of acts would be classed as terrorism and, predictably, prosecuted: hoax bomb threats; rhetorical threats of violence, unfulfillable and never intended to be fulfilled; politically-motivated action which has disruptive effects on the community (blockades, demonstrations, strikes); even the threat of organising such action. 
In order to prevent the use of the 2000 Act becoming oppressive, unworkable or both, extensive use of discretion has to be assumed. ${ }^{13}$ In other words, the Act should not be read as criminalising every type of action it describes but as enabling the police to do so, in contexts and situations where they judge that this is appropriate. This discretionary mindset is reflected in some of the specific provisions of the Act. Section 57 criminalises the possession of any article "in circumstances which give rise to a reasonable suspicion that [the] possession is for a purpose connected with the commission, preparation or instigation of an act of terrorism"; section 58 criminalises the collection or possession of "information of a kind likely to be useful to a person committing or preparing an act of terrorism”. A supplementary measure, Schedule 7, enables police officers at ports and airports to question transiting passengers, for up to nine hours, to determine whether they have been concerned "in the commission, preparation or instigation of acts of terrorism"; there is no requirement for the officer to have any grounds to suspect that this is the case.

In effect, the Act gives the police extensive powers of politicization and de-politicization. The point is not that (for example) jihadists' stated objectives should or can be incorporated into the discourse of liberal democracy; this is undesirable and probably impossible. What the discretionary "terrorist" framing does is to set the outer boundary of even potentially acceptable political discourse. Advocating ideas beyond this boundary is enough to bring an individual into suspicion. Thus in 2007, jihadist sympathiser Samina Malik, found in possession of a copy of the "Terrorist's Handbook", was found guilty under section 58 of the Terrorism Act ${ }^{14}$; earlier the same year Robert Cottage, a neo-Fascist, had been arrested in possession of bomb-making equiment and a garage full of explosive chemicals, and charged only with possession of explosives. ${ }^{15}$ Significantly, research on Schedule 7 detentions suggests that the proportion of Asian travellers detained exceeds the proportion in the travelling population by a factor of $11 .{ }^{16}$ Details on these detentions are not available, but the nine-hour detention of David Miranda in 2013 - apparently based on the suspicion 
that he was carrying information provided by the whistleblower Edward Snowden - demonstrates how widely the net of Schedule 7 can be cast. ${ }^{17}$

In short, in determining whether an individual's actions bring them within the purview of the 2000 Act, the key questions are not about the actions they may have committed but about the political goals of the individual - and these questions are not addressed by the Act itself. The Act creates an arsenal of powers which can be used against people who are classed by the authorities as potential terrorist suspects on the grounds of their political activities - and, in particular, on the grounds of their holding inadmissible political goals.

\section{Resilience as a goal, resilience as a tactic}

Societal resilience to exogenous shocks - such as the assertion of a political programme unacceptable enough to be classed as "terrorist" - responds both to the disruption of the shock itself and to the destabilisation among existing elites caused by the new actor's arrival. The model in Table 1 can be recast as follows:

\section{Table 2: Types of state defined by effects of new political entrants ABOUT HERE}

This typology of state types enables us to identify conditions under which a new and alien political intervention will bring normal political business to a halt (disruption) and/or cause political uncertainty (destabilisation). The fewer the points of access to the political system for new entrants - which is to say, the less normal it is for non-political groups in civil society to express themselves in 'political' terms - the more unacceptable an innovative or exogenous political intervention will be, and hence the more likely it will be to be received as disruption. As polities tend more towards a 
fragmentary and anarchic state, or towards an ideally and porously representative democracy, the possibilities of disruption diminish. Destabilisation, by contrast, is made possible by the existence of a multiplicity of power centres. Once new political contenders have emerged, this multiplicity creates the possibility of their finding elite allies - or at least the credible suspicion among other political actors that this might be possible. The more a state exhibits the top-down unity characteristic of the ideal direct democracy - or of an unaccountable autocracy - the less vulnerable it is to destabilisation.

The single most resilient state for a political system is thus direct democracy, in the sense of a system combining executive unity (minimising destabilisation) with an infinitely extensible range of points of access to the system (minimising disruption). Conversely, the type of state most vulnerable to both disruption and destabilisation, and hence in most need of strategies of resilience, is the pure oligopoly model, which cannot easily reverse both its lack of points of access from below and its lack of executive concentration. Oligopolies resist the disruption of a new political entrant in the shadow of the fear of degenerating into anarchy; once a new entrant has emerged, they negotiate the resulting destabilisation under the temptation of reverting to autocracy. The route to direct democracy - the state least vulnerable to either destabilisation or disruption - is difficult to find and rarely sought.

Within an oligopoly - the state type to which most contemporary capitalist democracies approximate - resilience in the face of terrorism is a two-stage process, responding to the disruption of a new contender and managing the subsequent destabilisation of existing power relationships. This second stage is likely to take a similar form to the negotiation of a "protest cycle" or "cycle of contention": the ideological repertoire of legitimate politics either expands, to neutralise the 
challenge by including some element of the contentious ideology in more or less neutralised form, or contracts, to eliminate any suspicion of overlap with the delegitimated challenger. ${ }^{18}$

This process of negotiation itself may leave a polity in a more or less resilient state. An inclusive negotiating process will produce an increased openness to influence from outside the political system; if it is accompanied by greater unity of purpose among elites, this will create the possibility of development towards the highly resilient "direct democracy" pole. Where the negotiation is exclusive, its closure may accentuate the elites' lack of openness to outside influence elite and hence entrench the "oligopoly" model; at worst, this result may itself be achieved on the basis of elite consensus, creating the conditions for development towards the "autocracy" model. Thus, in the Italian 1960s "cycle of contention" mapped by Tarrow, the development of a broader range of legitimate tactics of political activism was accompanied by a broad societal consensus in favour of the representation of organised labour. In the subsequent late-1970s cycle of contention, a beleaguered political class responded to innovative forms of activism by narrowing the range of admissible tactics and actors. When disruption causes destabilisation, dysfunctional forms of resilience like this may leave the polity in a state in which its vulnerability to further disruption is unchanged, or even increased.

\section{Not just violent extremism: the contradictory evolution of Prevent}

This process of exclusion and negative resilience - meeting the challenge of destabilisation by closing the polity to new entrants, and thereby increasing the risk of disruption - is exemplified by the development of the British government's "Prevent" programme. Prevent is an explicitly ideological initiative, de-politicizing - removing from the range of political acceptance - a certain kind of political project and aiming to reduce the number of individuals involved in it. How this aim 
is articulated can tell us a lot both about how the British government articulates the ideological threat presented by Islamist terrorism and about the government's approach to engagement with it and, by extension, the ultimate effect on the polity of this engagement.

Initiated in 2003, PREVENT (generally capitalised at this stage) was the counter-radicalisation strand of the British government's post-9/11 counter-terrorism strategy "CONTEST". It had the policy aim of "preventing terrorism by tackling the radicalisation of individuals" ${ }^{19}$; by implication, terrorists were individuals who had been through a process of radicalisation. In the original outline of the Prevent strategy, radicalisation is defined in general terms as " $[\mathrm{t}]$ he processes whereby certain experiences and events in a person's life cause them to become radicalised, to the extent of turning to violence to resolve perceived grievances. ${ }^{20}$ The definition is incoherent: to be "radicalised" is both to undergo a certain kind of influence and to be influenced to the point of reaching a set end-point ("turning to violence"). Implicitly, radicalisation itself is defined as radicalisation with a particular result.

A subsequent, more detailed discussion offers qualifications:

An alienated individual who has become highly radicalised is not necessarily a terrorist. Only a tiny minority of radicalised individuals actually cross over to become terrorists: by financing, lending facilities to, or encouraging active terrorists, or by actively participating in terrorist attacks.

There are a range of potential factors in radicalisation and no single factor predominates. It is likely the catalyst for any given individual becoming a terrorist will be a combination of different factors particular to that person. ${ }^{21}$ 
Three specific factors are identified. First, "the development of a sense of grievance and injustice"; this is associated with the adoption of "highly negative and partial" readings of history, and in particular "a simplistic, but virulent anti-Westernism" and the belief that "the West is antipathetic to Islam". Second, "a sense of personal alienation or community disadvantage, arising from socioeconomic factors such as discrimination, social exclusion, and lack of opportunity”. Third, “exposure to radical ideas", whether through "reading radical literature on Islamic and other subjects" "surfing the Internet", or from local contacts: "[e]xposure to a forceful and inspiring figure, already committed to extremism, can be important" 22 .

The document defines the specific form of "radicalism" associated with radicalisation to the point of identifying the key set of beliefs involved. However, it is not clear whether holding these beliefs, in whatever form, is in itself a problem: it is recognised that the majority of those who hold radical ideas are not involved in terrorism. The key transition - and one which states have a legitimate interest in preventing - is the process through which "a tiny minority" of individuals who are already radicalised "actually cross over to become terrorists". However, this key transition is not made the focus of any sustained attention; indeed, the incoherence of the concept of "radicalisation" serves to divert attention away from it.

The reference to multiple and unpredictable combinations of radicalising factors calls into question the extent to which any programme to counter radicalisation can address such a protean reality. The specific factors identified are imprecisely defined, but they correspond broadly to three distinct types of influence: ideological ("radical ideas", "virulent anti-Westernism"); social ("socioeconomic factors such as discrimination, social exclusion, and lack of opportunity"); and emotive (“a sense of grievance and injustice", "a sense of personal alienation or community disadvantage"). 
The last of these is not a factor in its own right so much as an effect which may precede the effect of radicalisation: the substantive factors identified are social and ideological. Neither has any predictive power: it is stressed that few who hold radical ideas go on to become terrorists, while the range of those affected by socio-economic disadvantage and discrimination is even broader. In any case, the reference to "addressing structural problems ... that may contribute to radicalisation" 23 is left unsubstantiated; it is not proposed that PREVENT activities should extend to broader social interventions to improve the lot of minority communities.

The key set of radicalising factors against which PREVENT's interventions are aimed is purely ideological. The proposed interventions are either ideological in themselves ("challenging the ideological motivations that extremists believe justify the use of violence") or designed to obstruct the dissemination of unwanted ideologies ("deterring those who facilitate terrorism and those who encourage others to become terrorists", "working with communities to help them discourage susceptible individuals from turning towards extremist activity") ${ }^{24}$. The report fails to identify any factors in radicalisation which are not experienced by many people who are in no danger of becoming terrorists. The reference to "susceptible" individuals is suggestive, but what this susceptibility consists of (or how it could be identified except in hindsight) is unclear.

Developed in 2003, Prevent in its original form was made public in 2006, as part of the government's response to the $7 / 7$ bombings the previous year. The same wave of legislative activity gave rise to the Terrorism Act 2006, which introduced new offences of "Encouragement of terrorism" (construed, controversially, to include "glorifying" past terrorist acts) and "Dissemination of terrorist publications". While, at least in its final form, the legislation is hedged about with qualifications and defences, the Act essentially introduces offences of lending out the wrong sort of document and expressing the wrong sort of views, in each case with a maximum 
prison term of seven years. Both provisions suggested that the government was focusing on radicalisation in the broadest sense, treating Islamist and jihadist views as a "terrorist" menace in themselves; the caveats expressed in the original Prevent document are not reflected in the legislation.

\section{Prevent achieves coherence - at a price}

The second iteration of Prevent, published as part of the Contest 2 strategy in 2009, resolves the incoherence of the original strategy at the cost of a drastic narrowing of focus. A new definition of radicalisation is offered, at first sight reproducing the old definition's central ambiguity: "radicalisation refers to the process by which people come to support terrorism and violent extremism and, in some cases, then to join terrorist groups"25. However, the new strategy's approach to radicalisation is unambiguous: "The aim of the Prevent workstream is to stop radicalisation, reducing support for terrorism and discouraging people from becoming terrorists." 26 The earlier strategy's equivocation between legitimate and dangerous forms of radicalism is resolved: to become radicalised, according to this definition, is not simply to acquire radical views but, as a minimum, to become a supporter of terrorism; radicalisation can thus be seen as a problem in its own right.

The revised strategy has five goals:

- challenge the ideology behind violent extremism and support mainstream voices

- disrupt those who promote violent extremism and support the places where they operate

- support individuals who are vulnerable to recruitment, or have already been recruited by violent extremists 
- increase the resilience of communities to violent extremism, and

- address the grievances which ideologues are exploiting. ${ }^{27}$

The term "violent extremism" is central to the narrative presented by these goals. Violent extremism has exponents, who promote it and make recruits to their ranks by propounding its underlying ideology; they prey on individuals who are vulnerable and invade communities which are lacking in resilience. The new strategy echoes the social concerns alluded to by the first strategy to the extent of referring to grievances which are being exploited by the ideologues of violent extremism, and which should be addressed in order to deprive them of ideological ammunition. Otherwise, the framework within which violent extremism and its proponents are considered is entirely ideological. "Violent extremism" is not presented as the radical extreme of a legitimate spectrum of opinion, but as a discrete (and identifiable) body of ideas in its own right; the social conditions which may contribute to individual radicalisation are reduced to a vocabulary of weaknesses and vulnerabilities, factors which may impair defences against violent extremism.

However, it is ideological in an unusual sense. The problematic ideas grouped under the heading of "violent extremism" are not presented as propositions to be challenged or refuted, but as an alien influence to be resisted. Support is to be offered at several levels: for individuals "vulnerable to recruitment ... by violent extremists"; for "mainstream voices" offering ideological alternatives to violent extremism; for the settings where promoters of violent extremism operate; and for the communities whose lack of "resilience" enables them to operate. More negatively, the promoters of violent extremism are to be "disrupted". These are less political activists than the ideological equivalent of a plague-carrier or a drug-pusher. In this context, the discussion of "individuals who are vulnerable to recruitment" is revealing. The report explains that vulnerability has many dimensions: 
Apologists for violent extremism very often target individuals who, for a range of reasons, are vulnerable to their messages. Vulnerability is not simply a result of actual or perceived grievances. It may be the result of family or peer pressure, the absence of positive mentors and role models, a crisis of identity, links to criminality including other forms of violence, exposure to traumatic events (here or overseas), or changing circumstances (e.g. a new environment following migration and asylum). ${ }^{28}$

If peer pressure, the lack of a role model, involvement in crime, trauma and migration can all be factors tending towards radicalisation, it is hard to imagine that any of them has any great predictive power. Rather, these are seen as debilitating influences making an individual more "vulnerable to [the] messages" of violent extremists; in this model of radicalisation, the messages themselves are doing all the work.

In its structure, the strategy is strongly reminiscent of the school of crime prevention associated with 'routine activity' theory. According to the theory, "A crime occurs when the offender escapes handlers [and] finds targets free from guardians in settings not watched by managers"29. Each of the new goals of Prevent can be recast in this language: the aim is to "increase the resilience of communities" by adding guardians to targets ("vulnerable individuals") and adding managers ("mainstream voices") to settings ("the places where [violent extremists] operate"), as well as ensuring that "handlers" are in place to prevent anyone who has been radicalised from radicalising others.

The terms "violent extremism" and "violent extremist" are key elements of this approach. The phrase "violent extremist" presumably signifies an individual who believes in achieving extreme 
ends by violent means (rather than an extremist who is also violent, as distinct from a violent moderate). Since the label of "violent extremist" would attach to everyone who holds that belief, it would be possible to be an entirely non-violent "violent extremist". At the same time, the phrase has the rhetorical strength of implying that a certain body of ideas is inherently linked with violence, to such an extent that anyone who holds those ideas can be classed as "violent". Its effect is to delegitimate both the ideas and anyone who holds them, setting them outside the scope of political debate: "violent extremism" can no more be tolerated than violence itself. Prevent 2 thus maintains the ideological focus of the original Prevent programme but resolves its ambiguity by essentialising a particular type of radical ideas.

The discourse of "violent extremism" can be seen as a key move in an exclusive engagement with the disruptive incomer of Islamism. Its use tended to frame Islamism as a disruptive and antipolitical ideology with which there could be no dialogue - and hence to narrow the legitimate political spectrum, excluding or calling into question those who believed in allowing such a dialogue to take place. This development can be set in the context of a continuing process of politicking and (de-)politicization, involving counter-terrorist agencies working with Muslim communities. The essentialising of "violent extremism", conflating terrorist involvement with holding views similar to those held by terrorists, was thus an exercise in politicking, aiming to forestall the destabilisation which could be caused by the political recognition of radical Islamism in any form. Some researchers pushed back against this process, arguing for engagement with Muslims who held "radical" views: "Muslim groups able to fully understand and communicate on a theological and political level with 'extremists' are better placed to assist and advise counterterrorism practitioners than Muslims who have no experience in this are" ${ }^{30}$. However, these were minority voices. The threat of destabilisation was felt within the agencies dealing with disruption; it 
was and addressed by drawing an ideological line which ensured that any engagement with radical Islamism was exclusive rather than inclusive.

\section{Draining the swamp: the ideological turn is entrenched}

After the Coalition government took office in 2010 the Prevent strategy was revised for a second time. The term "violent extremism" was abandoned; "radicalisation" was now defined as "the process by which a person comes to support terrorism and forms of extremism leading to terrorism" 31 . The vexed term "extremism" is also given its own definition, as "vocal or active opposition to fundamental British values, including democracy, the rule of law, individual liberty and mutual respect and tolerance of different faiths and beliefs" 32 .

The aim of Prevent in this revision is "to stop people becoming terrorists or supporting terrorism" 33 . It has three specific objectives:

- respond to the ideological challenge of terrorism and the threat we face from those who promote it;

- prevent people from being drawn into terrorism and ensure that they are given appropriate advice and support; and

- work with sectors and institutions where there are risks of radicalisation which we need to address.

The formulations on which these objectives rest effectively resolve the ambiguities of earlier versions of Prevent. Radicalisation does not have to include actual recruitment, but neither is it simply a matter of acquiring the wrong ideas; it has to include coming to support terrorism. Some 
forms of extremism may themselves be cause for concern, but they must be engaged in actively or vocally. The only major ambiguity is in the reference to 'forms of extremism leading to terrorism'; it is not clear how this relationship between extremism and terrorism is identified, in other words whether a particular extremist group has to have actual links with terrorist activity to be characterised in this way.

These formal continuities apart, most of the key features of the second version of Prevent have now disappeared or been downplayed: the term 'violent extremism'; the presentation of radicalisation as an experience of conversion (or infection) rather than a process; the 'plague-carrier' or 'pusher' model, with promoters of radical ideas preying on vulnerable individuals; the 'crime prevention' approach, counteracting the baleful influence of the extremists by strengthening mainstream voices and developing community resilience. These omissions, together with the new and more precise definition of radicalisation, suggest that at least some contributions to the revision of the strategy were made with a view to mitigating the effects of earlier politicking and bringing about a less exclusive engagement.

There is one key continuity with earlier versions of Prevent, which is associated with a notable innovation. The continuity is its ideological orientation, a constant throughout the development of the programme. The second Prevent strategy's single-minded focus on "violent extremism" had had much greater potential for political delegitimation and chilling of debate than the more incoherent original strategy. The third Prevent strategy, with its clearly articulated references to active alignment with terrorist groups, greatly restricted the ideological canvas; the report even acknowledged concerns that earlier Prevent interventions had been "disproportionate and intrusive" and "restricted free speech" ${ }^{34}$. However, this gain in focus was always uncertain; in practice it was largely undone by the key innovation of the third strategy: a focus on 'extremism' more broadly. 
In this second revision of Prevent, the broader and more interventionist objectives of addressing individuals' grievances and enhancing the resilience of communities are explicitly abandoned; the report suggests that these objectives "encouraged the use of Prevent funding and Prevent delivery structures for a very wide range of projects, some of them more to do with cohesion than with counter-terrorism" 35 . The implication is that the distinctiveness of Prevent had been lost through the delivery of Prevent initiatives within a broader "community cohesion" framework ${ }^{36}$; as a result, the implementation of Prevent had led to an inclusive engagement with Muslim groups, tending towards the expansion of the legitimate political sphere rather than its contraction. It is repeatedly emphasised that this will not happen in future:

there have been some cases where groups whom we would now consider to support an extremist ideology have received funding. Stricter monitoring is required to ensure this does not happen in future.

In future, neither Prevent funding nor support will be given to organisations that hold extremist views or support terrorist-related activity of any kind

Funding will not be provided to extremist organisations. It will not be part of this strategy to use extremists to deal with the risk from radicalisation.

[we] will not fund or work with extremist groups ${ }^{37}$

The politicking efforts which had led to the ideological focus of the second iteration of Prevent had been renewed, and taken up by groups such as the think tank Policy Exchange ${ }^{38}$. The arguments for 
disengagement with radical Muslims put forward by groups such as Policy Exchange had fallen on receptive ears. While the report argues that Prevent needs to "challenge extremist ideas where they form part of a terrorist narrative" ${ }^{39}$, this argument is undercut by minatory references to extremist views which "can provide the building blocks for a fully-fledged terrorist ideology" and "are espoused by apparently non-violent organisations very often operating within the law" ${ }^{40}$. The implication is that lawful and non-violent extremism can, on occasion, be reclassified as only apparently non-violent. Hence, the "connection between extremist and terrorist ideologies" should be emphasised; it is a goal of Prevent to "reduce the appeal of the political element of extremist ideology to people who might be attracted to terrorism" 41 . The effort to combat terrorist disruption the forcible self-expression of disallowed political actors - has merged into an effort to pre-empt destabilisation, by reducing the influence of a political incomer viewed as already having been granted political legitimacy.

Prevent in its original form, which finds some echo in the more precise formulations of the 2011 report, took a fundamentally ideological, politicising approach to Islamist radicals: disruption was addressed in ideological terms, using de-legitimated beliefs as a means of selecting a target population for discretionary counter-terrorist policing and investigation. In its third - and current iteration, Prevent is also characterised by an exclusive approach to potential ideological destabilisation, in reaction against the more inclusive experience of community-based counterterrorism efforts; as a result, it tends to treat Islamist radicals as promoters and enablers of terrorism even when their own activities are non-violent and legal.

The month before the review of Prevent was published, US Special Forces killed Osama bin Laden. Answering questions on the bin Laden operation in the House of Commons, the Prime Minister 
David Cameron referred to Prevent and used two heavily loaded images to describe extremist groups and ideologies:

there has been a pernicious ideology among a minority of some communities that has given some comfort to the stories that al-Qaeda provides ... We have to address that issue in order to drain the swamp in which al-Qaeda has been swimming

we must combat not just violent extremism, but extremism itself. I think there has in the past been a sense of a conveyor belt, with some extremist groups and organisations taking people into a career of jihadism, and we will never deal with that unless we deal with the conveyor belt itself. ${ }^{42}$

Following the May 2013 murder of Lee Rigby, a "Task Force" on extremism and radicalisation was formed. Announcing the new group, the Prime Minister was unambiguous: "Since coming into government we have made sure the Prevent Strategy focuses on all forms of extremism - not just violent extremism". Cameron again stressed the role of ideology: "It is as if for some young people there is a conveyor belt to radicalisation that has poisoned their minds with sick and perverted ideas ... It is not enough to target and go after violent extremists after they have become violent. We have to drain the swamp which they inhabit." 43

\section{Conclusion: containing disruption, preventing destabilisation, promoting vulnerability?}

From the outset, the Prevent strategy has been predicated on the presentation of a "radical" ideology (Islamism in particular, more or less unspecified forms) as politically unacceptable and hence a disruptive influence. Successive versions of the Prevent strategy used the concept of 
"radicalisation" to (de-)politicize radical Islamist ideas, but did so in different ways. For the initial Prevent programme, radicalisation might or might not be the precursor to terrorist activity; the move to terrorist involvement was seen as a higher level of radicalisation, or an additional transition which might follow an achieved state of radicalisation. This nuanced but ambivalent model was swept away by the certainties of the second Prevent strategy, for which "violent extremism" was an ideological contagion: conversion to "violent extremism" was brought about by an encounter between a promoter of violent extremism and a vulnerable subject, facilitated by taking place in the setting of a community lacking in resilience. The 2011 version of Prevent returned to a more straightforwardly ideological framing; within this framing, however, the problematic end-state to be deterred was identified as alignment with terrorism, rather than any form of free-standing ideological radicalism.

However, the effect of this clarification was reversed by a reaction within the counter-terrorist establishment against the potentially destabilising effect of engagement with radical Islam; this led to the conflation of ideological radicalism in general with the undesirable, terrorist-aligned form of radicalism, effectively collapsing the distinction between radicalism and alignment with terrorism. Thus Cameron's 2011 and 2013 statements situated radical ideas themselves as a "conveyor belt" to violence, and the milieu in which those ideas are accepted as a "swamp" - a source of inevitable contagion - which must be eradicated if terrorism is to be prevented. Exclusionary politicking, focusing on the threat of destabilisation, thus triumphed over the possibility of an inclusive engagement. The language of inexorable disruption, and of a contaminating influence which must be excluded at all costs, bespeak the exclusive engagement with Islamism to which the government is now committed. 
This exclusive approach has been one element of Prevent from the outset; that its effects in practice have often been more constructive and inclusive is an unintended consequence of the delivery of Prevent through autonomous local initiatives. To the extent that the emphatically exclusive approach heralded by Cameron in 2011 is replicated at local level, the result is likely to be the progressive delegitimation of broad swathes of opinion and a decrease in the political pluralism of British society. In terms of Bourbeau's typology, "change at the margin", involving the politicization of previously uncontentious beliefs and practices, will have been brought about through the politicking of groups opposed to the inclusion of radical Islamist groups within the polity. In terms of the state typology outlined earlier, the effect will be to ward off destabilisation by entrenching the polity as an "oligopoly": making it more rather than less closed to political incomers; increasing rather than reducing the range of ideologies held to be inadmissible; and hence making the polity more rather than less vulnerable to disruption.

The final irony is that the existing apparatus of Prevent may be too well established, and integrated with "community cohesion" initiatives, for a shift to exclusive engagement to be feasible ${ }^{44}$. Local commitment to inclusive engagement, and hence to the expansion rather than contraction of the polity, may yet save the government from itself. 
${ }^{1}$ Leena Malkki \& Teemu Sinkkonen, "Political Resilience to Terrorism in Europe: Introduction to the Special Issues," in this volume.

2 David Snow and Robert Benford, "Ideology, frame resonance, and participant mobilisation," in Bert Klandermans, Hanspeter Kriesi and Sidney Tarrow, eds., From structure to action (London: JAI, 1988).

${ }^{3}$ Hanspeter Kriesi, "The political opportunity structure of new social movements: its impact on their mobilisation", in J. Craig Jenkins and Bert Klandermans, eds., The Politics of Social Protest (London: UCL Press, 1995), p. 171.

${ }^{4}$ Paul Ginsborg, A history of contemporary Italy (London: Penguin, 1990), p. 155.

${ }^{5}$ Martin Innes, "Policing Uncertainty: Countering Terror through Community Intelligence and Democratic Policing," The ANNALS of the American Academy of Political and Social Science 605 (2006), p. 223.

${ }^{6}$ Philippe Bourbeau, "Resiliencism: Premises and Promises in Securitisation Research," Resilience: International Policies, Practices and Discourses 1 (1) (2013), p. 12.

${ }^{7}$ Author's figures.

8 "Deaths in police custody," online at $<$ http://www.inquest.org.uk/statistics/deaths-in-police-custody $>$ (last accessed 22 March 2014).

${ }^{9}$ HM Government, Number of fatalities resulting from road accidents in Great Britain, online at

$<$ https://www.gov.uk/government/publications/annual-road-fatalities> (last accessed 7 July 2015).

${ }^{10}$ Jeremy Waldron, Torture, terror, and trade-offs (Oxford: Oxford University Press, 2010), p. 65.

${ }^{11}$ Prevention of Terrorism (Temporary Provisions) Act 1974 s9(1).

12 Terrorism Act $2000 \mathrm{~s} 1$ (as passed).

13 See P. A. J. Waddington, "Slippery slopes and civil libertarian pessimism," Policing and Society 15(3) (2005), but also Dirk Haubrich, "Anti-terrorism Laws and Slippery Slopes: A reply to Waddington," Policing and Society 16(4) (2006).

${ }^{14}$ Haroon Siddique, “"Lyrical terrorist' convicted over hate records,” Guardian, 8 November 2007.

${ }^{15}$ Duncan Campbell, "Ex-BNP candidate jailed for stockpiling explosives," Guardian 31 July 2007.

${ }^{16}$ Equality and Human Rights Commission (EHRC), An Experimental Analysis of Examinations and Detentions under Schedule 7 of the Terrorism Act 2000, EHRC Briefing paper 8 (Manchester: EHRC, 2013).

17 "Glenn Greenwald's partner detained at Heathrow airport for nine hours", Guardian, 19 August 2013.

18 Sidney Tarrow, Democracy and disorder (Oxford: Oxford University Press, 1989),

Sidney Tarrow, Power in movement (Cambridge: Cambridge University Press, 1998), Phil Edwards, "Autonomia and the political: an Italian cycle of contention, 1972-79," Modern Italy 11(3) (2006), Phil Edwards, "'More work! Less Pay! "Rebellion and repression in Italy, 1972-7, (Manchester: Manchester University Press, 2009).

${ }^{19}$ HM Government, Countering International Terrorism: The United Kingdom's Strategy, Cm 6888 (2006), p. 9.

${ }^{20}$ HM Government, Countering International Terrorism, p. 9.

${ }^{21}$ HM Government, Countering International Terrorism, p. 10.

${ }^{22}$ HM Government, Countering International Terrorism, p. 10.

${ }^{23}$ HM Government, Countering International Terrorism, p. 11.

${ }^{24}$ HM Government, Countering International Terrorism, p. 12, 13.

${ }^{25}$ HM Government, The United Kingdom's Strategy For Countering International Terrorism, Cm 7547 (2009), p. 82, emphasis added.

${ }^{26}$ HM Government, The United Kingdom's Strategy for Countering International Terrorism, p. 82.

${ }^{27}$ HM Government, The United Kingdom's Strategy for Countering International Terrorism, p 83.

${ }^{28}$ HM Government, The United Kingdom's Strategy for Countering International Terrorism, p. 89.

${ }^{29}$ Marcus Felson, "Routine activity approach," in Richard Wortley and Lorraine Mazerolle, eds., Environmental criminology and crime analysis (Abingdon: Routledge, 2008), p. 74.

${ }^{30}$ Basia Spalek and Laura Zahra McDonald, "Terror Crime Prevention: Constructing Muslim Practices and Beliefs as 'Anti-Social' and 'Extreme' through CONTEST 2,' Social Policy and Society 9(1) (2010), p. 126.

${ }^{31}$ HM Government, Prevent Strategy, Cm 8092 (2011). 108.

${ }^{32}$ HM Government, Prevent Strategy, p. 107-8.

${ }^{33}$ HM Government, Prevent Strategy, p. 6.

${ }^{34}$ HM Government, Prevent Strategy, p. 8.

${ }^{35}$ HM Government, Prevent Strategy, p. 27.

${ }^{36}$ Therese O'Toole, Daniel Nilsson DeHanas and Tariq Modood, "Balancing tolerance, security and Muslim engagement in the United Kingdom: the impact of the 'Prevent' agenda," Critical Studies on Terrorism 5(3) (2012). 
${ }^{37}$ HM Government, Prevent Strategy, pp. 24, 35, 39, 55.

${ }^{38}$ Shiraz Maher and Martyn Frampton, Choosing our friends wisely: Criteria for engagement with Muslim groups (London: Policy Exchange, 2009); see also Tom Mills, Tom Griffin and David Miller, The cold war on British Muslims: An Examination of Policy Exchange and the Centre for Social Cohesion (Glasgow: SpinWatch, 2011).

${ }^{39}$ HM Government, Prevent Strategy, p. 50, emphasis added.

${ }^{40}$ HM Government, Prevent Strategy, p. 83, 50.

${ }^{41}$ HM Government, Prevent Strategy, p. 53, 52.

${ }^{42}$ David Cameron, Statement to House of Commons. HC, Deb 3 May 2011 cc 461, 473.

${ }^{43}$ David Cameron, Statement to House of Commons. HC Deb 3 June 2013 cc 1235, 1245.

${ }^{44} \mathrm{O}$ 'Toole et al, "Balancing tolerance, security and Muslim engagement," p. 386. 